\title{
Implementing and Controlling an Operations Strategy in Global Industrial Service Networks
}

\author{
Andreas Nobs ${ }^{1}$, André Minkus ${ }^{2}$ and Andreas Rummert ${ }^{3}$ \\ 1 ETH Zurich, Center for Enterprise Sciences (BWI) \\ Kreuzplatz 5, 8032 Zurich, Switzerland \\ anobs@ethz.ch, Tel: +41446320531 \\ 2 aminkus@ethz.ch, Tel: +41 446320527 \\ 3 Opitzstrasse 31, 22301 Hamburg, Germany \\ andreas@rummert.com, Tel: +49 4036121258
}

\begin{abstract}
The importance of industrial service implies an increasing need for principles to design and manage the associated operations. This paper focuses on the information exchanges in globally decentralised service networks. It thereby emphasises cross-functional interactions from an operations strategy perspective. A balanced scorecard framework is then proposed in order to facilitate the implementation and controlling of the information operations. It was found that its application fosters the strategic coordination of the operational action in a decentralised service organisation.
\end{abstract}

Keywords

Industrial Service, Service Operations Strategy, Information Management, Balanced Scorecard

\section{Introduction}

\subsection{Motivation and Problem}

Industrial service is the supply of after-sales services (e.g. installing, training, repairing, upgrading and disposing) including tangibles such as spare parts and consumables related to the maintenance of industrial goods [1]. This service is of ever-increasing importance for manufacturers of durable capital goods for several reasons. Due to the concentration on core competencies and the growing complexity of the machinery, there is a rising demand for maintenance and support, since customers use capital goods as a resource in their own operations. Therefore, the 
aftermarket of an installed base provides manufacturers with new sources of revenues which tend to have higher margins than the income from the core products $[2,3]$. Second, services are more difficult to imitate than mere technical features of the core products and, hence, they offer the providers a differentiation potential and a source of competitive advantage. Finally, the characteristic direct customer involvement permits after-sales service functions to gather market information (e.g. application failures, customer requirements, or competitors' activities). This in turn constitutes an essential input to product and service development, especially in the area of capital goods [4].

In this context, the ability to efficiently manage service process related information from different sources became an important success factor for the performance of the whole business. Chase et al. [5, 6] already pointed to the competitive potentials of the service factory, which emphasises cross-functional support from the manufacturing to other functional departments through the exchange of skills, knowledge, and information. Nonetheless, evidence from our case studies shows that the corresponding operations often do not adequately satisfy the increased information requirements, neither concerning the downstream provision nor the upstream feedback of information [7]. In line with the findings of other research in the field, this situation reflects a typical challenge of a manufacturer becoming a decentralised service provider [8-10]. Firstly, it proves a corporate disregard in terms of the growing demand for and the strategic importance of the services. In addition, it demonstrates a specific coordination and controlling problem regarding the information processes in decentralised service organisations (cf. [11], pp. 197 et sqq.).

\subsection{Objective}

Manufacturers must deliberately optimise the cross-functional information interactions in order to capitalise on the strategic service potentials and to increase their business performance (cf. [12], pp. 535 et sqq.). This is not so much a question of technology, but strategy - the fact that the collaboration in the service network is considered a source of competitive advantage [5]. Companies, therefore, require a new approach facilitating the implementation and controlling of a comprehensive operations strategy in terms of information potentials within their global service. This new approach has to fulfil several requirements. First of all, it has to take into consideration all important competencies and information resources at different functional and organisational company units. Furthermore, since these units usually pursue different objectives according to their conventional division of tasks, it needs to integrate the different views towards a common corporate service perspective. It should provide the possibility to clarify and evaluate the mutual contributions of different company units to their respective performances.

In response to these purposes, the paper firstly integrates the boundary-spanning information interactions into a service operations strategy framework. A balanced scorecard approach is then applied to translate the framework into explicit target areas in order to make transparent the expected operational action based on a common understanding of the relations throughout the organisation. 


\section{Information Resources in the Distributed Service Organisation}

\subsection{Organisational Structure and Information Exchanges}

The provision of industrial service is a process consisting of different activities, which are carried out in a network of actors belonging to various functions and organisational units [10]. The high degree of customer contact and the intensity of front-line operations require first level service units close to the customer [13]. In connection with the ongoing business internationalisation, the customer proximity necessitates a multi-site expansion of the service organisation [14]. This can be achieved with own local subsidiaries or via independent third party service providers, such as agencies or dealers. Due to the high complexity of the products, the local front-line units are typically backed by central support functions which provide second level assistance [15]. The support centres form the major interface to various other central company and plant departments (e.g. research \& development or production \& assembly) as well as to suppliers, which all provide third level assistance in case of specific problems that can not directly be solved by the service personnel.

The three level support structure implies complicated information interactions between the different company units (cf. [16]). These relationships may be analysed by means of a service mapping methodology [17]. A service map generally facilitates the identification of the patterns and organising principles in the service business processes [18]. This is complemented with an information logic in order to demonstrate the rational connections through information resources within the service systems [7]. On the one hand, this depicts information that run from the central functions "downstream" to the front-line units, building an important resource for the service delivery. This flow comprises, for instance, technical documentation, manuals, and instructions, which are usually prepared by the central service based on the inputs from the preliminary departments, such as design plans from $R \& D$, or inspection sheets from assembly. Other examples are direct technical advice and support as well as education and training provided from second level functions to the local service units. On the other hand, there exists an "upstream" information flow, from the market back to centralised functions. At first, this encompasses requests, inquiries, and all sorts of orders. Moreover, as already introduced above, the market units posses or are at the source of crucial information, both, about the installed base as well as about the customers and how they actually use the products. This information on market and competitive trends needs to be captured, since it serves as one of the most precious inputs for the improvement, redesign, or new development of products and services. Hence, market information, such as for example service histories or front-line personnel's experiences and improvement propositions should flow back to the central company departments.

\subsection{Operations Strategy Perspective}

In general, an operations strategy is the pattern of decisions which shape the capabilities to meet long-term corporate and business objectives through the 
reconciliation of market requirements with operations resources [19]. On the one hand, it describes the required operations performance driven by customer needs, competitor activity, and therefore market positioning. On the other hand, it specifies the nature and characteristics of its resources that produce the market performance. Given the market needs in a specific situation, the actual decisions in the operations strategy pertain to the company's resources. The decision categories are usually divided into structural and infrastructural categories (see [20], pp. 31 et seq.). The operations strategy defines the integration of these aspects. Internally, it deals with the fit between structural and infrastructural choices and between different functional areas. External integration aligns the strategic decision areas with the performance objectives [21].

Central to service is the explicit consideration of the nature of customer contact in the so-called service encounter, which takes account of the customer's relationship to and interaction with the service delivery [22]. It implies specific characteristics (see [23], pp. 63 et sqq.) which are considered in a dimension-oriented delineation of a service system by means of potentials, processes, and results. They correspond to the operations strategy aspects and they constitute an operations logic in which the resources and capabilities (potential) are transformed (process) into desired outputs according to customers' needs and expectations (result) (cf. [15], p. 22). This framework is now applied to the service information resources in scope and it thereby explicitly adds the strategic perspective. It builds the basis to identify and specify the information contributions and requirements from different organisational and functional units within a globally decentralised service network.

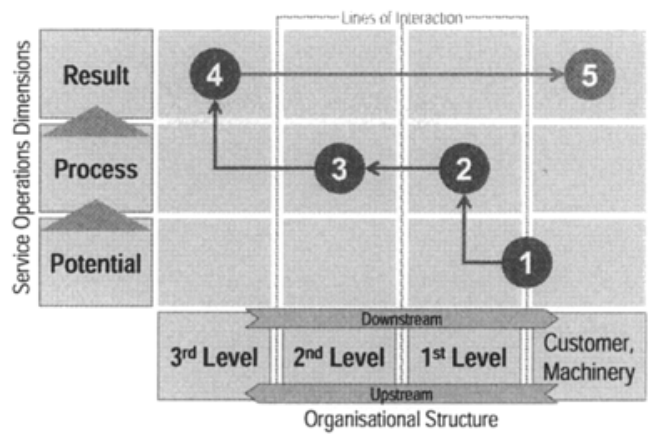

Fig. 1. Information Interaction Matrix

Figure 1 exemplifies the generic integration of the three service operations dimensions with the organisational structure previously outlined. The resulting matrix specifies that the latter is depicted on the horizontal axis and the operations dimensions be arranged consecutively from bottom to top along the vertical axis. Structural relationships between the organisational units are indicated by vertical dotted lines that locate the moments of interaction between organisational units. The explicit consideration of the customer and machinery highlights the fact that it is part of the delivery system. This setup again draws upon the service mapping principles. 
The matrix illustrates a simplified upstream information relation. One might think of a structural constructive failure the field technician identifies based on customer interaction or a concrete technical improvement proposal (1). This insight is reported (2) to the central service which analyses and prepares the information about the installed base for the respective functions (3), for instance $R \& D$, where the proposal may lead to a revised technical design (4), and therefore enhances the quality of the product offering (5) that the customer is potentially willing to pay for.

\section{Industrial Service Strategy Map}

A Balanced Scorecard (BSC) framework is now applied to integrate the information requirements into a comprehensive picture of the service business and to derive operational implementation and controlling measures in the service organisation. Kaplan and Norton [24] introduced the BSC as a performance measurement system to translate an organisation's strategic goals into operational action (i.e. through more tangible goals, actions, and performance measures). The objectives and measures of the scorecard thereby not only focus on a financial perspective, but rather take into account a balanced view of three other performance areas: customer, internal business processes, and innovation, learning and growth. The so-called strategy map illustrates the linkages between the four perspectives through a chart of cause-andeffect relationships between different target areas [25]. This central method is adapted to the three service operations dimensions with appropriate target areas in order to identify meaningful objectives as well as to derive manageable measures turning the information requirements to operational action (cf. [26]).

The financial perspective emphasises the overall business performance in terms of tangible goals. The target areas here involve aspects of profitability, revenue growth, or market shares. This level may be viewed part of the result dimension. It is considered and measured in order to control whether the service organisation's operations strategy, its implementation and execution are really contributing to the bottom line, since some of the assumed linkages between operating performance and financial success may be quite uncertain in a particular application. Furthermore, the financial perspective bridges the gap to the business strategy, which finally governs the financial targets. The second perspective focuses on customer satisfaction and retention, which, according to the service-profit chain concept [27], are the most important drivers for growth and profitability. It thus directly corresponds to the result dimension and stresses target areas related to the overall availability of goods and services, including choice, quality, delivery time, and the pricing of the offerings. The process perspective highlights critical operations that enable the service organisation to satisfy the strived results and customer needs. They cover the operational assignment of the essential resources in order to develop, improve, and provide the industrial service and the related goods. The industrial service strategy map here covers aspects of information and knowledge processing as well as the development and provision of goods and services. It thereby stresses the horizontal and vertical cooperation within the service network. Finally, the potential perspective includes objectives and measures for the promotion of competencies, assets, and 
cultural aspects that enable the organisation to effectively perform customer-based and internal processes. This specifically implies to capture the relevant drivers for future innovation and growth in the areas of human, information, and organisation capital [28]. Figure 2 exhibits an example strategy map regarding the upstream report information previously outlined (cf. fig. 1). It defines the strived objectives in the four perspectives in terms of the information interaction and relates them into relationships, similar to causal loop diagrams (cf. [29]).

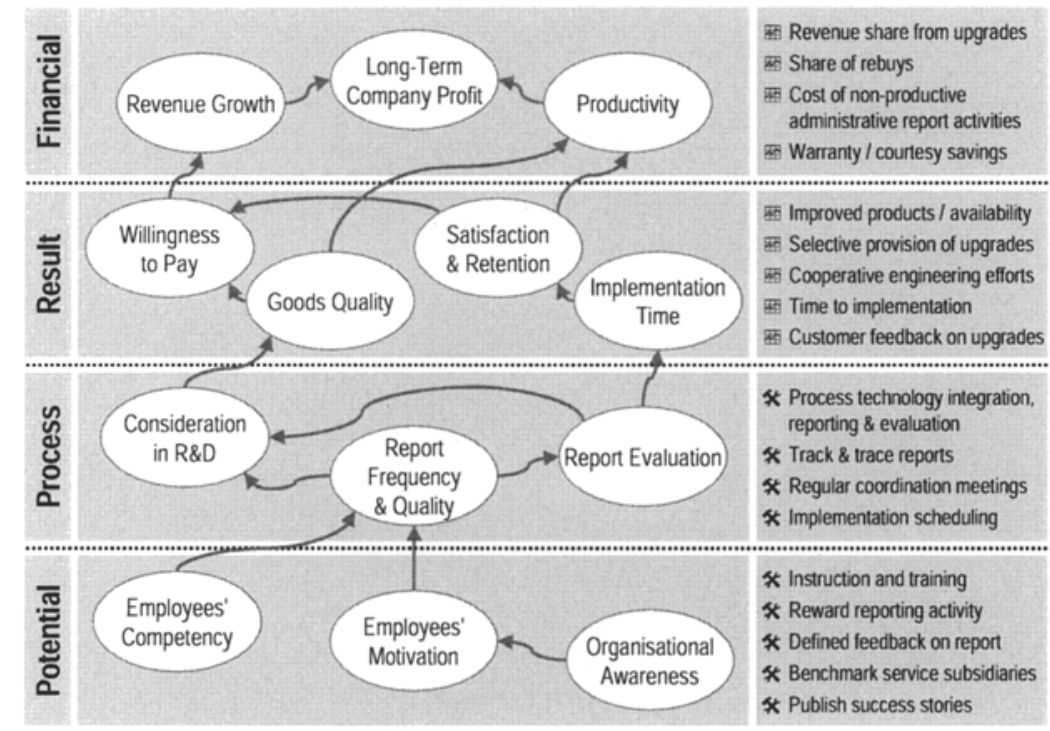

Fig. 2. Industrial Service Strategy Map

This comprehensive picture of objectives is the basis to derive operational activities with corresponding performance indicators (as exemplified on the right hand side). The lower two perspectives thereby mainly address the implementation of measures concerning structural and infrastructural decision categories, whereas the upper perspectives primarily contain aspects to control the performance outcomes.

\section{Implications and Benefits}

Manufacturers must increasingly adapt their service systems in order to tap the associated economic and competitive potentials. The outlined strategy map provides a suitable concept in consideration of the stated requirements and objectives. It shows the value chain by which a service organisation converts its information resources into desired operational, market, and financial performance. It specifically identifies the driving forces (in terms of potentials and processes) to meet the market needs. This external integration is the necessary condition for a successful 
implementation of an operations strategy. Moreover, the framework highlights the importance of cooperation in a distributed service organisation. The example in figure 2 demonstrates the relevance of front-line information provided by local service units for the improvement of goods and services, which, in turn, drives the performance of the whole business. This ability to effectively communicate corporate initiatives and operational measures throughout the company is an important benefit of the strategy map. The understanding of the underlying values and hypotheses improves organisational clarity, which in turn facilitates the internal alignment of structural and infrastructural resources across vertically diversified functional company units.

The target areas and objectives are specified from an integrated point of view. The derived operational measures and the performance indicators are then attached to the pertaining organisational units according to the service maps (simplified in fig. 1). This means that the actual implementation maintains the diversification of the operations through measures that are influenced by the decentralised units. The controlling, however, ensures that the operational action and improvement stay in line with the defined overall network objectives. Hence, the performance measurement of the integrative operations should be assigned to the central service function in order to control the success of the implementation and the need for corrective action. To stick with the example, activities to enhance employees' motivation and competency to report market information need to be measured with the frequency and quality of the reports. Such indicators are compared with the implementation in R\&D and product improvements, their further impact on customer satisfaction and, finally, sales figures. In addition, this offers the possibility to benchmark the performance of different service units in order to identify particularly successful practices, which in turn allows exchanging these practices horizontally.

The coordinated implementation of the service operations and especially its subsequent controlling and reviewing eventually increases the organisational awareness for and consensus on the strategic service importance. It therefore contributes as a valuable instrument to support the change process towards service system integration in manufacturing companies.

\section{References}

1. P. Johansson and J. Olhager, Industrial service profiling: Matching service offerings and processes, Int. J. Production Economics 89, 309-320 (2004).

2. R. Wise and P. Baumgartner, Go Downstream - The New Profit Imperative in Manufacturing, Harvard Business Rev., Sept-Oct, 133-141 (1999).

3. J. Behlke and K. Banki, VDMA-Kennzahlen Kundendienst (VDMA, Frankfurt a.M., 2005).

4. T. Levitt, After the sale is over..., Harvard Business Rev., Sept-Oct, 87-93 (1983).

5. R.B. Chase and D.A. Garvin, The Service Factory, Harvard Business Rev., Jul-Aug, 61-69 (1989).

6. R.B. Chase, K.R. Kumar, and W.E. Youngdahl, Service-based Manufacturing: The Service Factory, Production and Operations Management 1 (2), 175-184 (1992). 
7. A. Nobs, A. Minkus, and T. Pengo, Towards a Process Reference Model for the Management of Industrial Services, in: Exploiting the Knowledge Economy, ed. by P. Cunningham and M. Cunningham (IOS Press, Amsterdam, 2006), pp. 1072-1079.

8. R. Oliva and R. Kallenberg, Managing the transition from products to services, Int. J. Service Industry Management 14 (2), 160-172 (2003).

9. S. Brax, A manufacturer becoming service provider - challenges and a paradox, Managing Service Quality 15 (2), 142-155 (2005).

10. P. Gaiardelli, N. Saccani, and L. Songini, Performance measurement systems in after-sales service: an integrated approach, Int. J. Business Performance Management 9 (2), 145-171 (2007).

11. A.V. Hill, D.A. Collier, C.M. Froehle, J.C. Goodale, R.D. Metters, and R. Verma, Research opportunities in service process design, J. Operations Management 20, 189-202 (2002).

12. A. Picot, R. Reichwald, and R.T. Wigand, Die grenzenlose Unternehmung: Information, Organisation und Management (Gabler, Wiesbaden, 2003).

13. M.A. Cohen, N. Agrawal, and V. Agrawal, Winning in the Aftermarket, Harvard Business Rev., May, 129-138 (2006).

14. C.P. McLaughlin and J.A. Fitzsimmons, Strategies for globalizing service operations, Int. J. Service Industry Management 7 (4), $43-57$ (1996).

15. I. Hartel, Virtuelle Servicekooperationen: Management von Dienstleistungen in der Investitionsgüterindustrie (vdf, Zürich, 2004).

16. B.J. Berkley and A. Gupta, Identifying the information requirements to deliver quality service, Int. J. Service Industry Management 6 (5), 16-35 (1995).

17. J. Kingman-Brundage, Service Mapping: Back to Basics, in: Understanding Services Management, ed. by W.J. Glynn and J.G. Barnes (John Wiley \& Sons, Chichester, 1995), pp. 119-142.

18. J. Kingman-Brundage and W.R. George, Service logic: achieving service system integration, Int. J. Service Industry Management 6 (4), 20-39 (1995).

19. N. Slack and M. Lewis, Operations Strategy (Pearson Education, Harlow, 2002).

20. M. Rudberg and J. Olhager, Manufacturing networks and supply chains: an operations strategy perspective, Omega 31, 29-39 (2003).

21. A.V. Roth and L.J. Menor, Insights into Service Operations Management: A Research Agenda, Production and Operations Management 12 (2), 145-164 (2003).

22. G.L. Shostack, Designing services that deliver, Harvard Business Rev., Jan-Feb, 133-139 (1984).

23. H. Meffert and M. Bruhn, Dienstleistungsmarketing: Grundlagen - Konzepte - Methoden (Gabler, Wiesbaden, 2006).

24. R.S. Kaplan and D.P. Norton, The Balanced Scorecard - Measures That Drive Performance, Harvard Business Rev., Jan-Feb, 71-79 (1992).

25. R.S. Kaplan and D.P. Norton, Having Trouble with Your Strategy? Then Map It, Harvard Business Rev., Sept-Oct, 167-176 (2000).

26. A. Assiri, M. Zairi, and R. Eid, How to profit from the balanced scorecard: An implementation roadmap, Ind. Management \& Data Systems 106 (7), 937-952 (2006).

27. J.L. Heskett, T.O. Jones, G.W. Loveman, W.E. Sasser Jr., and L.A. Schlesinger, Putting the Service-Profit Chain to Work, Harvard Business Rev, Mar-Apr, 164-174 (1994).

28. R.S. Kaplan and D.P. Norton, Measuring the Strategic Readiness of Intangible Assets, Harvard Business Rev., Feb, 52-63 (2004).

29. F. Schoeneborn, Controlling Service Business at a German Printing Press Manufacturer, in: Proc. $19^{\text {th }}$ Int. Conf. System Dynamics Soc., 23-27 Jul 2001, ed. by J.H. Hines, V.G. Diker, R.S. Langer, and J.I. Rowe (2002). 